JHR

33,6

Received 6 November 2018 Revised 3 January 2019 21 February 2019 Accepted 11 March 2019

\section{Predictors of quality of life of the rural older adults in Northern Thailand}

\author{
Katekaew Seangpraw \\ School of Medicine, University of Phayao, Phayao, Thailand \\ Nop T. Ratanasiripong \\ School of Nursing, \\ California State University - Dominguez Hills, Carson, California, USA, and \\ Paul Ratanasiripong \\ California State University - Long Beach, California, USA
}

\begin{abstract}
Abstract
Purpose - The purpose of this paper to explore socio-demographic factors related to the quality of life (QoL) among older adults in the rural area of Thailand.

Design/methodology/approach - This cross-sectional study examined socio-demographic factor that may predict the QoL among 470 older adults who lived in a rural area of Northern Thailand. The study questionnaire consisted of four parts, including socio-demographic data, perceptions of the health status, family relationship and QoL (WHOQOL-OLD). Spearman's $\rho$ or Pearson's product moment correlation coefficients were determine the factors associated with the QoL. Stepwise multiple regressions were carried out to describe predictors of the QoL.

Findings - Majority of the participants (71 percent) were between 60 and 79 years old. Three-quarters of participants had primary school educational level. Most (74 percent) were married and no longer work (72 percent). Most (87 percent) had a moderate level of the QoL in all six domains. Six predictors of QoL include age, gender, education, current employment, health status perception and family relationship. These factors could significantly predict the QoL of the older adults by 30 percent.

Originality/value - Public health officers should collaborate with community partners and relevant stakeholders to increase the QoL of older adults in the rural area through activities which promote health status perception and family relationship.
\end{abstract}

Keywords Quality of life, Older adults, Rural society, Thailand

Paper type Research paper

\section{Introduction}

Globally, there are $841 \mathrm{~m}$ older adults (aged 60 years or older) with this number predicted to double by 2050[1]. In Thailand too, the aging population is increasing rapidly. In 2015, there were over $10.7 \mathrm{~m}$ older adults, approximately 15 percent of the total population[2]. This percentage of Thailand's older adult population will likely be at least 30 percent of the total Thai population by 2035[2].

The increase in the elderly population continuously impacts the national economy, resources on health care and society as a whole[1]. As individuals, older adults will face a

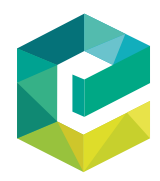

(C) Katekaew Seangpraw, Nop T. Ratanasiripong and Paul Ratanasiripong. Published in Journal of Health Research. Published by Emerald Publishing Limited. This article is published under the Creative Commons Attribution (CC BY 4.0) licence. Anyone may reproduce, distribute, translate and create derivative works of this article (for both commercial and non-commercial purposes), subject to full attribution to the original publication and authors. The full terms of this licence may be seen at http://creativecommons.org/licences/by/4.0/legalcode

This study was financially supported by a grant from the University of Phayao (Grant No. R060078). This study was conducted after an Institutional Review Board approval was obtained on September 07, 2015 (ID no. 2/0.34/58). The authors would like to thank all participants in the study. 
decline in physical health, mental health, social activities and quality of life (QoL). As older adults age, they will likely have a higher chance of encountering significant health concerns such as hearing impairment, vision impairment, memory loss, arthritis, osteoporosis, hypertension, heart disease and diabetes. They will also be more susceptible to infectious diseases (i.e. influenza, pneumococcal disease)[3, 4]. Furthermore, while older adults may gain more wisdom, their learning processes may be slower[4]. They may also be struggling with the loss of income, increased medical care costs and the loss of significant others[5].

QoL is one of the indicators of a healthy life. As defined by the World Health Organization, a person's QoL is “an individual's perception of life in the context of the cultural system and the values in which they live, perceive themselves, expectations, standards, and concerns"[6]. It is a multidimensional assessment of an individual's ability in relation to their physical, mental, social assets and can convey the overall well-being of life as a whole[7].

Studies have been conducted to examine the QoL among the older adult population in both developed and developing countries. A study conducted among 911 older adults in the USA showed that, on average, each subject had 2.5 chronic conditions and received health care two to nine times annually. Some dimensions of the QoL were associated with depression, memory problems and activities of daily living[8]. Moreover, in cases where older adults do not have a good family relationship, their QoL may be impacted since family members provide significant support to older adults in the form of caregiving during periods of physical sickness, providing emotional support, helping older adults to solve problems when required and staying close to older adults so that they will feel less lonely[9, 10].

In a study conducted in Iran, overall, the older adults had an acceptable QoL in both genders. The total score of QoL was related to health conditions (i.e. hearing/vision impairment, cardiovascular disease, respiratory disease and gastrointestinal diseases)[11]. In a Thai national study, 55 percent of older adults reported that their health was not good and only 52 percent had undergone a general physical check-up in the past 12 months[2]. However, the study mainly emphasized the demographic and social characteristics, leaving the QoL and health aspects unanswered.

Phayao province in the Northern Part of Thailand is mostly comprised of an Eastern Lanna ethnic group population who speak a unique northern dialect. The elderly proportion in Phayao has increased from 7.4 percent in 1992 to 15.3 percent in 2015[12]. The percentage of dependent older adults also increased from 7.4 percent in 2011 to 18.6 percent in 2012[12]. The majority of older adults in Phayao have limited or no formal education and most work in the agricultural fields[12], which is a contributing factor to their lack of preparation for aging and physical deterioration. Currently, there is very limited data on the QoL among this population in Northern Thailand. One study in 2012 found that over two-thirds of the older adults living in Phayao enjoyed a fair level of QoL. The study reported that the predictors of the QoL included income, activity during the day, alcohol consumption and present illness[13]. However, the study did not examine the extent to which family relationships and the perceptions of health status influenced the QoL among older adults. Therefore, this study aimed to assess socio-demographic factors, perceptions of the health status and family relationships which may predict the QoL among older adults in the rural areas of Thailand.

\section{Methods}

\section{Participants}

There are 15 sub-districts with 4,891 seniors living in the Muang district of Phayao province[14]. These sub-districts are in the rural area located $\sim 30 \mathrm{~km}$ from Muang district, Phayao. Ban Tum and Ban Tom sub-districts were chosen as the target population. The sample was selected using the two-stage cluster sampling method (Figure 1). The appropriate sample size for estimating the proportion of the population was calculated with 95 percent of reliability, the QoL of seniors
Predictors of QoL 


\section{JHR}

33,6

\section{2}

Figure 1.

A diagram of the cluster sampling

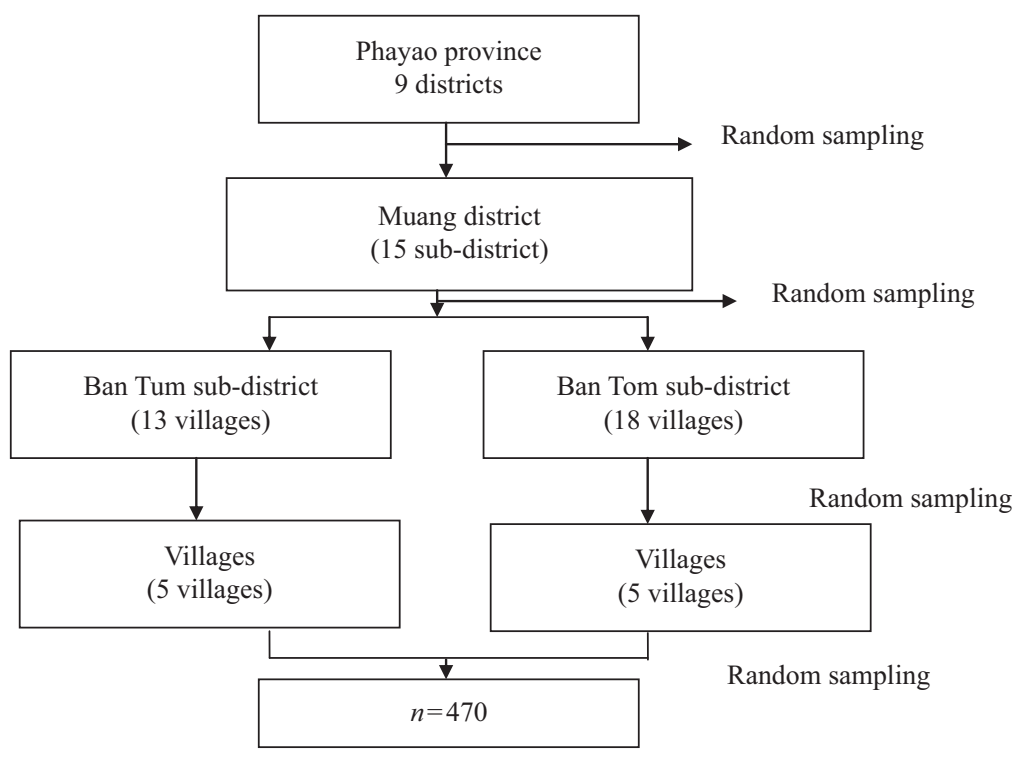

at 17.2 percent[15] and accepted value of error for 3.42 percent of older adults. The sample size calculated by formula sampling[16] was 427 older adults:

$$
\begin{gathered}
n=\frac{\mathrm{Np}(1-p) Z_{1-a / 2}^{2}}{d^{2}(N-1)+p(1-p) Z_{1-a / 2}^{2}}, \\
n=\frac{4,891 \times 0.172(1-0.172) 1.96^{2}}{0.0342^{2}(4,891-1)+0.172(1-0.172) 1.96^{2}} \\
n=427,
\end{gathered}
$$

where $n$ is the sample size; $N$ is the population; $p$ is the proportion; $Z_{1-\alpha / 2}=1.96$ and $d$ is the error.

In addition, per the calculation formula, the sampling group was increased by 10 percent in order to obtain the required number of participants and to cover incomplete data, making a total sample size of 470 older adults.

The inclusion criteria included older adults who were at least 60 years old, lived in the chosen Muang District for more than six months, were able to speak Thai, and voluntarily participated in this study. The exclusion criteria included older adults who had recognition difficulties and/or other disabilities such as dementia, psychosis, intellectual disability, blindness and deafness.

\section{Measurement}

The study questionnaire was comprised of four parts. Part I contained socio-demographic items. Part II consisted of 15 items regarding each participant's perceptions of their health status. This part was adapted from the self-esteem and health conception of the elderly community in the area including three-dimensions; clinical health perception with the following question; "You have always understood your illness," functional health perception assessed by the following question; "You understand your health and immunity," and adaptive health perception with the following question; "You are prepared to cope with any illness that 
may happen in the future" $[17,18]$. The participants rated each item from 1 to 5 . We divided the level using the applicable criteria based on cut point[17] score range as 15-75 (15-50 points $=$ low, 51-62 points $=$ moderate and $63-75$ points $=$ high). Part III contained 14 items asking participants to rate their relationship with their family. This part was adapted from family relationship questionnaires that were locally contextualized[17]. The original family relationship scale contained three items; in this study five items were used. We modified the Likert's type of responses from 3 levels to 5 levels. The base cut point $[18,19]$ score range was from 14 to 70 (14-47 points = need improvement, 48-58 points $=$ moderate and $59-70$ points = good). Part IV consisted of 24 items including questions for the older adults about their QoL. This part was adapted from the QoL questionnaire created by the WHO (WHO-QOL-Old)[20, 21]. The questionnaire was adjusted to meet the context of the rural community. The questionnaire was divided into six domains: sensory abilities, autonomy, past/present/future activities, social participation, death and dying and intimacy. Participants rated each item from 1 to 5 . The possible score range was $24-120(\leqslant 72$ points $=$ low QoL, 73-95 points $=$ moderate $\mathrm{QoL}$ and $96-120$ points $=$ good $\mathrm{QoL})$.

The questionnaire was examined for its content validity by three qualified experts (a researcher specialized in health behaviors from the Thai Ministry of Health, a professor specialized in aging and public health, and a professor specialized in aging and nursing). The questionnaire was revised and piloted with 30 older adults who lived in a similar environment, but not from the chosen two sub-districts. Cronbach's $\alpha$ coefficients were utilized to check the internal reliability of the scales. The reliability coefficients remain consistent: perception of health $=0.78$, family relations $=0.80$ and $\mathrm{QoL}=0.79$.

Before the data collection, 15 university students (majoring in community health) and ten village health volunteers who were registered by the Ministry of Public Health were trained to be the research assistants. They were taught the research study protocol, consent process and how to conduct a structured interview. The research assistants went to each sub-district and invited the potential subjects to participate in the survey. If the older adults were interested in participating, the research assistant would read an informed consent to the older adults in their local language. If the older adults agreed to participate, they would sign the informed consent. Then the research assistant would interview each participant by reading the questionnaire items and ask the participant to rate each item. There were 470 older adults who participated in the study.

\section{Ethical consideration}

The current study was approved by the ethics committee of the Research Institute UP-HEC University of Phayao (2/034/58).

\section{Data analysis}

The data were analyzed using the Statistical Package for the Social Sciences version 20.0 (License from University of Phayao). Descriptive statistics were used to examine the socio-demographic and variable characteristics of the participants. Depending on the level of measurement of the variables, Spearman's $\rho$ or Pearson's Product Moment correlation coefficients were used to determine the factors associated with the QoL of participants. Stepwise multiple regression was also applied to identify the predictors of the QoL. A $p$-value was set to consider as statistically significant at $p<0.05$.

\section{Results}

The average age of all participants was $68.8(\mathrm{SD}=7.1$, Range $=60-91)$ with most of them (71.1 percent) between 60 and 79 years old. Slightly more than half of the participants were female (52.1 percent). Approximately, three-quarters of participants had not completed further studies and were educated up to primary school level. Most were married (74 percent) 
JHR

33,6

and no longer worked (71.7 percent). More than half of the participants (59.1 percent) had a monthly income of less than 4,000 Thai Baht (equivalent to $\$ 130)$. Most of them (91.9 percent) had participated in community activities. Many of the participants (58.5 percent) reported that they had at least one health condition including hypertension (49.5 percent), stress (16.3 percent), diabetes (14.2 percent), muscle pain (13.0 percent) and gout (7.0 percent) (Table I).

\section{4}

Variables of interest

Among the 470 older adults, the mean score of perceived health status was 49.9 ( $\mathrm{SD}=6.5$, Min. =40, Max. =68). Only 13.5 percent of older adults had a high perception of their health condition and habits. Approximately, a quarter (23.4 percent) had high family relationship scores while the rest had low to moderate family relationship scores. The mean score of $\mathrm{QoL}$ among older adults was $87.4(\mathrm{SD}=5.8, \mathrm{Min} .=70, \mathrm{Max} .=108)$. Most of them (87.2 percent) had a moderate level of QoL (Table II).

When examining the correlations of the variables of interest and QoL, there were significantly positive associations among gender, marital status, education, current employment, health condition, community participation, health status perception, family relationships and the QoL. Significantly, age was negatively associated with the QoL of the participants $(\phi<0.001)$ (Table III).

When the significant factors were entered into the stepwise multiple regression model, six predictors (age, gender, current employment, education, health status perception and family relationship) were found to be the factors which had the power to predict the QoL of rural older adults in this study $\left(R^{2}=0.357, R^{2}\right.$ change $=0.302, p$-value $\left.<0.05\right)$ (Table IV).

\begin{tabular}{|c|c|c|}
\hline Socio-demographic & $n$ & $\%$ \\
\hline $\begin{array}{l}\text { Age (years) } \\
60-79 \\
\geqslant 80\end{array}$ & $\begin{array}{l}334 \\
136\end{array}$ & $\begin{array}{l}71.1 \\
28.9\end{array}$ \\
\hline $\begin{array}{l}\text { Gender } \\
\text { Male } \\
\text { Female }\end{array}$ & $\begin{array}{l}225 \\
245\end{array}$ & $\begin{array}{l}47.9 \\
52.1\end{array}$ \\
\hline $\begin{array}{l}\text { Marital status } \\
\text { Single/divorced/separated } \\
\text { Married }\end{array}$ & $\begin{array}{l}122 \\
348\end{array}$ & $\begin{array}{l}26.0 \\
74.0\end{array}$ \\
\hline $\begin{array}{l}\text { Education } \\
\text { No } \\
\text { Yes }\end{array}$ & $\begin{array}{l}315 \\
155\end{array}$ & $\begin{array}{l}67.0 \\
33.0\end{array}$ \\
\hline $\begin{array}{l}\text { Currently employment } \\
\text { No } \\
\text { Yes }\end{array}$ & $\begin{array}{l}337 \\
133\end{array}$ & $\begin{array}{l}71.7 \\
28.3\end{array}$ \\
\hline $\begin{array}{l}\text { Income per month (Baht) } \\
\leqslant 4,000 \\
\geqslant 4,001\end{array}$ & $\begin{array}{l}278 \\
192\end{array}$ & $\begin{array}{l}59.1 \\
40.9\end{array}$ \\
\hline $\begin{array}{l}\text { Community participation } \\
\text { No } \\
\text { Yes }\end{array}$ & $\begin{array}{r}38 \\
432\end{array}$ & $\begin{array}{r}8.1 \\
91.9\end{array}$ \\
\hline $\begin{array}{l}\text { Health condition } \\
\text { Without chronic disease } \\
\text { With chronic disease }\end{array}$ & $\begin{array}{l}195 \\
275\end{array}$ & $\begin{array}{l}41.5 \\
58.5\end{array}$ \\
\hline
\end{tabular}

Table I.

Socio-demographic characteristics among older adults
Without chronic disease 


\begin{tabular}{|c|c|c|c|}
\hline Variables & No. & $\%$ & Predictors \\
\hline $\begin{array}{l}\text { Health status perception } \\
\text { Low level (15-50) } \\
\text { Moderate level (51-62) } \\
\text { High level }(63-75) \\
\text { Mean }=54.23, \mathrm{SD}=7.114\end{array}$ & $\begin{array}{c}110 \\
297 \\
63\end{array}$ & $\begin{array}{l}23.3 \\
63.2 \\
13.5\end{array}$ & \\
\hline $\begin{array}{l}\text { Family relationship } \\
\text { Low level (14-47) } \\
\text { Moderate level (48-58) } \\
\text { High level }(59-70) \\
\text { Mean }=53.16, \mathrm{SD}=6.399\end{array}$ & $\begin{array}{c}53 \\
307 \\
110\end{array}$ & $\begin{array}{l}11.3 \\
65.3 \\
23.4\end{array}$ & o \\
\hline $\begin{array}{l}\text { Quality of life } \\
\text { Low level }(\leqslant 72) \\
\text { Moderate level }(73-95) \\
\text { High level }(96-120) \\
\text { Mean }=87.42, \mathrm{SD}=5.863\end{array}$ & $\begin{array}{c}21 \\
410 \\
39\end{array}$ & $\begin{array}{c}4.5 \\
87.2 \\
8.3\end{array}$ & $\begin{array}{r}\text { Table II. } \\
\text { Number and } \\
\text { percentage of the level } \\
\text { of the quality of life of } \\
\text { rural elderly }\end{array}$ \\
\hline
\end{tabular}

\section{Discussion}

The mean age of participants in this study was 68.8. Age is one of the indicators determining one's self-care ability[22]. Usually, the self-care ability will gradually be higher as a child grows up and it will be decreased when the person enters the aging process. When the physical and cognitive functions decline, the older adults will start to depend on others to help with their daily and social activities which, in turn, may decrease the overall QoL. In term of QoL as measured by WHO-QOL Old, the study found that as the older adults get older, their average QoL is lowered. More than half of older people experienced QoL at the low level, followed by the high level, and the moderate level. These results are similar to previous studies $[15,23]$ which reported that older adults had a lower QoL and higher levels of dependency compared to younger adults. In addition, as they begin to increasingly depend on others, they may feel that they become a burden to the family and society as well[24]. Health care professionals and the community should work hand-in-hand to encourage older adults to share their life experiences and valuable skills with the future generation which, in turn, may increase the older adults' self-esteem.

Gender is another predictor of $\mathrm{QoL}$ in older adults. Compared to males, female older adults seem to have a better QoL. One study in Thailand reported a significant association between gender and QoL in the elderly[11]. One reason why female older adults scored higher on QoL could be that the female older adults may have higher perceived social support from family and friends[25]. Helping older adults to stay connected with family, friends, and the community could increase their QoL. Public health agencies could set up programs and outreach activities to encourage older adults, especially males, to participate in community events.

This study also found that current employment and education can predict the QoL in older adults. The result is similar to previous studies[26, 27]. When older adults are retired or unemployed, they likely have less income to maintain their standards of living. They may have to borrow money from different sources or depend on their children for financial assistance[26]. Government welfare of 600 Thai Baht per month (less than $\$ 20$ ) does not meet the minimum basic needs of older adults who do not have a retirement pension. National welfare for older adults should be seriously discussed at the government's policy level. Creating suitable jobs for older adults who can still work may be needed along with connecting the elderly who can no longer work to family or community resources. In term of educational level, older adults with a higher level of education had more advantages. 
JHR

33,6

456

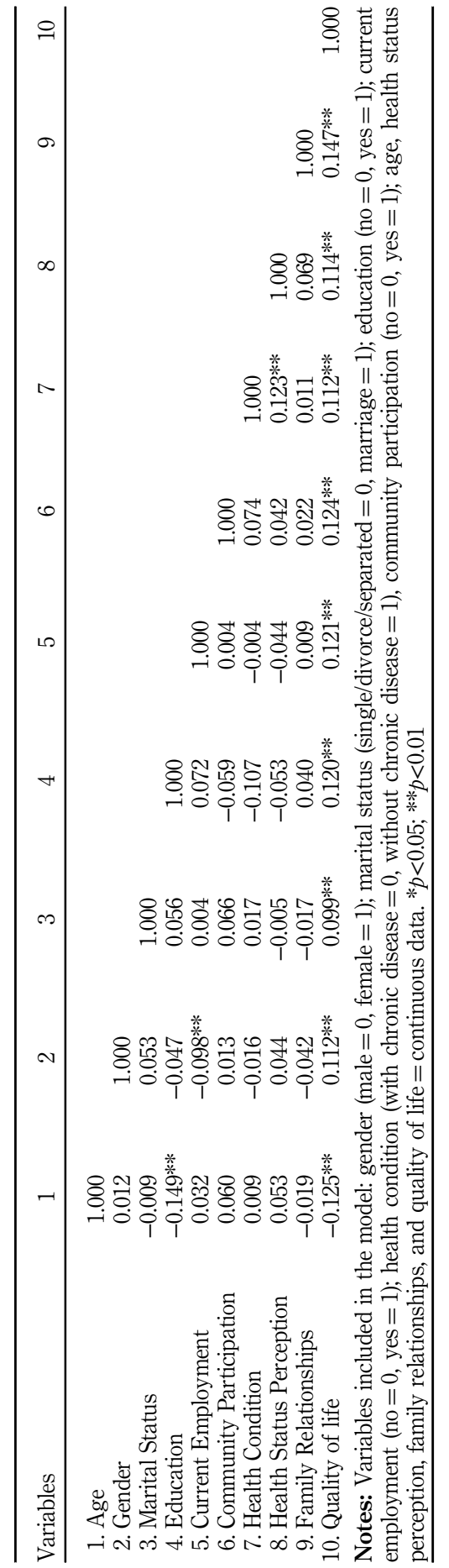

Table III.

Correlation

coefficients and

relationship between

predictors; it shows

by Correlation matrix

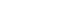


They may have better living conditions, less chance of being exposed to risk factors of diseases, less labor-intensive work, a good network of friends, and a higher sense of selfefficacy[27]. While advancing the formal education level may not be a goal for older adults, however, less formal and enjoyable learning experiences may be helpful. Creative short-term workshops or training (i.e. painting, basketry, herbal gardening, and massage) may also provide additional income for older adults.

The relationship with family is another key predictor of the QoL in older adults. A good relationship with family enhances the mental health of older adults, whilst older adults with good family relationship have a higher QoL since they may be able to depend on the family more and can express their feelings or concerns with significant others. The family is usually a source of love, warmth, and emotional support for the elderly. Health care personnel should encourage the family and elderly to participate in recreational activities or family vacations together in order to enhance the elderly's QoL[28, 29].

The last predictor of QoL in this study is health status perception. Health status perception is the idea and understanding of the process involved in performing a self-health assessment[18, 30]. More than half the participants had health status perceptions at a moderate level followed by low and high levels. This is probably because the majority of older adults were in the age range of 60-79 years old. While they may still be able to perform basic daily activities, their physical health deteriorates as their age increases[30]. This is consistent with a previous study which found that older adults who were able to take care of themselves and participate in community activities had a good perception of their health status. This conforms to the concept that the perception of good health is related to the seriousness of health-promoting behaviors[22].

In China, a population-based health-related QoL study was measured in 2010. The findings showed that as older adults aged, they had a higher number of physically unhealthy days (over 2.7 days/month). Among those over 75 years of age, there were reports of poorer health at almost 5 times higher than 18-24 year-olds[31]. Furthermore, with increased age, physical deterioration increases too. However, if the older adults perceive their health status in a more positive light, they may stay motivated to take good care of themselves and live longer leading to a good QoL[23]. Advising older adults to have a regular medical check-up at a local hospital may help increase the healthy days since some diseases may be prevented through self-care and primary prevention intervention. In order to increase positive perception of health status, a project such as "move it or lose it" (the less you move physically, the more you lose in health) may be implemented to teach and encourage older adults to keep moving (e.g. dancing, gardening, walking, and stretching). This will not only increase their physical movement but also increase their self-esteem in that they are still able to do various activities in life.

Income, community participation and health condition are not significant predictors of the QoL among older adults. However, these factors are still significantly related to QoL indicating

\begin{tabular}{|c|c|c|c|c|c|c|}
\hline Variables & $R^{2}$ & $R_{\text {change }}^{2}$ & $B$ & $\mathrm{SE}(\mathrm{B})$ & $\beta$ & $p$-value \\
\hline (Constant) & 0.357 & 0.302 & 84.297 & 1.951 & & \\
\hline Self-esteem & & & 0.622 & 0.395 & 0.116 & $<0.006$ \\
\hline Family relations & & & 4.381 & 1.543 & 0.127 & $<0.004$ \\
\hline Education & & & 1.397 & 0.553 & 0.112 & $<0.012$ \\
\hline Occupation & & & 1.437 & 0.580 & 0.110 & $<0.013$ \\
\hline Gender & & & 1.319 & 0.521 & 0.112 & $<0.017$ \\
\hline Age & & & -1.734 & 0.550 & -0.138 & $<0.002$ \\
\hline
\end{tabular}

Notes: Variables included in the model: gender $($ male $=0$, female $=1)$; education $($ no $=0$, yes $=1$ ); current employment $(\mathrm{no}=0$, yes $=1$ ); age, health status perception, family relationships, and quality of life $=$ continuous data

\section{Predictors of QoL}

Table IV. Stepwise multiple regression analysis between factors and quality of life among elderly 
JHR

33,6

the importance of these factors among older adults in term of social support[22, 30]. Public health organizations should influence policy makers to actively move forward with the government plan to increase financial aid (social welfare, allowance and welfare card) for low income elderly in order to alleviate the cost of living. Also, participating in community activities may help older adults increase their self-worth because they will be accepted by people in the community leading to increased life satisfaction and QoL[25]. This is consistent with a previous study which found that elderly people with chronic illness, who can take care of themselves, can motivate good behaviors of self-care practice. Moreover, they will remain in good health and do not need to rely on others[29].

This study had some limitations. This study was conducted among rural Thai older adults in one Thai province. It may not be generalizable to all rural older adults in other developing provinces. Also, health or disease condition data were self-reported. The older adults might have been diagnosed by a health care professional or self-diagnosed. Lastly, social environment and behaviors might influence how the older adults answered some questions such as the use of alcohol/tobacco, QoL, health status perceptions and family relationship.

\section{Conclusions}

The findings from this study contribute to the knowledge regarding the QoL amongst the older adult population. It found that self-esteem and family relationships are important for improving the QoL of the elderly. This study provided clear recommendations to increase the QoL of older adults by setting up health promotion programs to increase their physical and mental activities, the source of income, community involvement, family relationship and perception of health status.

\section{References}

1. United Nations [UN]. World population ageing 2013. [cited 2017 Oct 7]. Available from: www.un.org/ en/development/desa/population/publications/pdf/ageing/WorldPopulationAgeing2013.pdf

2. Knodel J, Teerawichitchainan B, Prachuabmoh V, Pothisiri W. The situation of Thailand's older population: an update based on the survey of older persons in Thailand; 2014. [cited 2017 Oct 7]. Available from: www.psc.isr.umich.edu/pubs/pdf/rr15-847.pdf

3. American Psychological Association. Older adults' health and age-related changes: reality versus myth. 2015 [cited 2017 Oct 7]. Available from: www.apa.org/pi/aging/resources/guides/older.aspx

4. Center of Disease Control and Prevention [CDC]. Healthy aging. Nonthaburi: Ministry of Public Health; 2015.

5. Pew Research Center. Growing old in America: expectations vs reality. 2009. [cited 2017 Oct7]. Available from: www.pewsocialtrends.org/2009/06/29/growing-old-in-america-expectations-vs-reality/

6. World Health Organization [WHO]. WHOQOL-BREF: introduction, administration, scoring and generic version of the assessment. Program on mental health. Geneva: WHO; 1996.

7. Sun W, Aodeng S, Tanimoto Y, Watanabe M, Han J, Wang B, et al. Quality of life (QOL) of the community-dwelling elderly and associated factors: a population-based study in urban areas of C China. Arch Gerontol Geriatr. 2015 Dec; 60(2): 311-16.

8. Baemholdt M, Hinton I, Yan G, Rose K, Mattos M. Factors associated with quality of life in older adults in the United States. Qual Life Res. 2012 Apr; 21(3): 537-34.

9. Noknoi C, Boripunt W. The quality of life of elders in Songkhla province. Princess Narathiwas Uni J. 2017 Sep-Dec; 9(3): 94-105.

10. Xavier FM, Ferraz MP, Marc N, Escosteguy NU, Moriguchi EH. Elderly people's definition of quality of life. Rev Bras Psiquiatr. 2003 Mar; 25(1): 31-39.

11. Khaje-Bishak Y, Payahoo L, Pourghasem B, Jafarabadi MA. Assessing the quality of life in elderly people and related factors in Tabriz Iran. J Caring Sci. 2014 Dec; 3(4): 257-63. 
12. Phayao Provincial Public Health Office, Thailand. Report demographic Phayao Office of the Federal Register in 2015. 2015. Phayao. [cited 2017 Oct 7]. Available from: www.phayao.go.th/au/pyoinfo7.pdf

13. Hongthong D, Somrongthong R, Ward P. Factors influencing the quality of life (QoL) among Thai older people in a rural area of Thailand. Iran J Public Health. 2015 Apr; 44(4): 479-85.

14. Hill Tribes Development Center Phayao. Annual report situation of Phayao province 2015. Phayao: Department of Social Development and Welfare, Ministry of Social Development and Human Security; 2015.

15. Myo Myint N, Sutham N, Chokchai M. Quality of life of the elderly people in Einme Township Irrawaddy Division, Myanmar. Asia J Public Health. 2010 Jul-Dec; 1(2):4-10.

16. Daniel WW. Biostatistics: a foundation for analysis in the health sciences. 4th ed. New York, NY: John Wiley \& Sons, Inc.; 1995.

17. Suwanpratheep N. Factor-related to adaptation of elderly with Ischemic heart disease. Master of Nursing Science Program in Gerontological Nursing. Bangsaen: The Faculty of Nursing, Burapha University; 2015.

18. Smith JA. The idea of health: a philosophical inquiry. ANS Adv Nurs Sci. 1981 Apr; 3(3): 43-50.

19. Namarak R. Family factors influencing exercise and eating behavior among elderly with overweight in Muang district, Nakhonpathom Provine. Bangsaen: The Faculty of Nursing, Burapha University; 2014.

20. Power M, Quinn K, Schmidt S WHOQOL-OLD Group (2005). Development of the WHOQOL-Old module. Qual Life Res. 2005 Dec; 14(10): 2197-214

21. World Health Organization [WHO]. WHO-QoL old manual. Copenhagen: WHO European Office; 2004.

22. Orem DE. Nursing: concepts of practice. 2nd ed. New York, NY: McGraw-Hill; 1980.

23. Chutidech J, Nawarat S, Chaweewan B, Nopporn H. Quality of life of rural elderly in Wangnamkheaw district Nakhonratchasima province. J Public Health. 2011 May-Aug; 41(3): 229-39.

24. Cahill E, Lewis LM, Barg, FK, Bogner HR. You don't want to burden them. J Fam Nurs. 2009 Aug; 15(3): 295-317.

25. Ali A, Hazarika PK. Gender, Quality of life and perceived social support among rural elderly population: a study from Sonitpur District Assam. Indian J Gerontol. 2016; 30(4): 441-51.

26. Mosca I, Nivakoski S. Income adequacy and quality of line in older age: evidence for the first three waves of the Irish longitudinal study on aging; 2006. [cited 2017 Oct 7]. Available from: www.tilda. tcd.ie/assets/pdf/IrishLifeReport.pdf

27. Colet CF, Mayorga P, Amador TA. Educational level, socio-economic status and relation with quality of life in elderly residents of the city of Porto Alegre/RS, Brazil. Bral J Pharm Sci. 2010 OctDec; 46(4): 805-10.

28. Morrow WR, Wilson RC. Family relations of bright high-achieving and under-achieving high schoolboys. Child Dev. 1961 Sep; 32: 501-10.

29. Aydin R, Unal E, Gokler ME, Metintas S, Emiral GO, Ozay O, Onsuz F, BIsikli B. An evaluation of home health care needs and Quality of Life among the elderly in a semi-rural area of Western Turkey. Eur Geriatr Med. 2016 Feb; 7(1): 8-12.

30. Chantakeeree C. Health promotion behavior of the elderly participating in activities at Lumpinee Park Bangkok Metropolis. Bangkok: Faculty of Nursing, Chulalongkorn University; 2006.

31. Dong WL, Li YC, Wang ZQ, Jiang YY, Mao F, Qi L, et al. Self-rated health and health-related quality of life among Chinese residents China 2010. Health Qual Life Outcomes. 2016 Jan; 14(5): 1-11.

\section{Corresponding author}

Katekaew Seangpraw can be contacted at: eungkaew@gmail.com

For instructions on how to order reprints of this article, please visit our website:

www.emeraldgrouppublishing.com/licensing/reprints.htm

Or contact us for further details: permissions@emeraldinsight.com 